\title{
Spectrophotometric Determination of Alzheimer's Drug, Memantine Hydrochloride in Biological Samples Using Ninhydrin and Ferric Chloride
}

\author{
Hany A. Omara ${ }^{1 *}$ and Hamid M. Younis ${ }^{2}$ \\ ${ }^{1}$ Chemistry Department, Preparatory Year Deanship, Aljouf University, Al Qurayyat, KSA \\ ${ }^{2}$ Faculty of Science, Chemistry Department, Sirt University, Sirte, Libya
}

\begin{abstract}
Two simple, rapid, accurate and precise spectrophotometric procedures have been developed for the determination of memantine $\mathrm{HCl}(\mathrm{MEM})$. The first method (A) is based on the interaction of ninhydrin in $N, N^{\prime}$ dimethylformamide $(D M F)$ medium, with primary amino group present in MEM. This reaction produced a bluepurple product, which absorbed maximally at $595 \mathrm{~nm}$. Beer's law is obeyed in the concentration range of 0.4$19.3 \mu \mathrm{g} / \mathrm{mL}$ with $\mathrm{RSD}$ of $0.88 \%$ and molar absorptivity of $1.12 \times 10^{4} \mathrm{~L} / \mathrm{mol} . \mathrm{cm}$ in addition to limits of detection and quantification. In second method $(B)$ MEM was reacted with ferric chloride solution, yellowish orange colored chromogen showed $\lambda_{\max }$ at $375 \mathrm{~nm}$ showing linearity in the concentration range of $0.3-9.7 \mu \mathrm{g} / \mathrm{mL}$ with RSD of $1.03 \%$ and molar absorptivity of $1.73 \times 10^{4} \mathrm{~L} / \mathrm{mol} . \mathrm{cm}$ in addition to limits of detection and quantification. The proposed method has been applied successfully to the analysis of the bulk drug and its dosage forms and spiked human plasma. No interference was observed from common pharmaceutical adjuvant. Statistical comparison of the results with the reference method shows excellent agreement and indicates no significant difference in accuracy and precision.
\end{abstract}

Keywords: Memantine HCl; Ninhydrin; Ferric Chloride; Spectrophotometric; Pharmaceutical Analysis; Spiked Human Plasma.

\section{Introduction}

Memantine hydrochloride is the first in a novel class of Alzheimer's disease medications acting on the glutamatergic system by blocking NMDA receptors. Eli Lilly and Company first synthesized it in 1968 as a potential agent to treat diabetes; the NMDA activity was discovered in the 1980s. MEM is an uncompetitive, moderate affinity N-methyl-D-aspartate (NMDA) receptor antagonist used for treating patients with moderate to severe Alzheimer's disease. The chemical name is 1-amino-3, 5-dimethyladamantane hydrochloride (CAS: $41100-52-1, \mathrm{C}_{12} \mathrm{H}_{21} \mathrm{~N} \cdot \mathrm{HCl}$ and M.W. $=215.77$, Scheme 1). It is believed that over stimulation of nerve cells by glutamate may be responsible for the degeneration of nerves in some neurological diseases such as Alzheimer's disease. Memantine hydrochloride is commercially available in the market because it is likely to show neuroprotective effect at a concentration used in the treatment of Alzheimer's disease and to slow down disease progression [1-5].

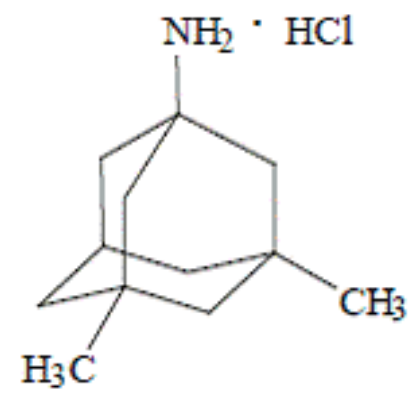

Scheme 1. Structure of memantine hydrochloride (MEM).

Stability indicating high performance liquid chromatographic method coupled with ultra violet detection has been applied in the determination of MEM in bulk.[6] High performance liquid chromatographic methods coupled with fluorescence detection have been reported in the literature for the quantification of MEM in rat plasma,[7, 8] human plasma.[9-11] Determination of memantine in human plasma by liquid chromatography with mass spectrometry (LC-MS),[12-15] gas chromatography with mass spectrometry (GC- 
MS) [16] and micellar electro kinetic chromatography (MEKC) [17], extractive-Spectrophotometric [18] oxidation-reduction reaction-spectrophotometric [19] or Potentiometrically [20, 21].

Though the above-mentioned chromatographic methods are sensitive, they are not suitable for routine analysis of the MEM in quality control laboratories. The methods suffer from one or more drawbacks such as expensive instrumentation, tedious extraction procedures, time consumption, complex and derivatization of the drug with suitable chromophores or fluorophores. Especially in developing countries, spectrophotometric method has generally been the method of choice for routine analysis in quality control laboratories. The spectrophotometric method is simpler, rapid, sensitive, selective and inexpensive. Spectrophotometric methods were reported $[22,23]$.

Ninhydrin (2, 2-Dihydroxyindane-1,3-dione) is a chemical used to detect ammonia or primary and secondary amines. When reacting with these free amines, a deep blue or purple color known as Ruhemann's purple is evolved $[24,25]$.

Ninhydrin is known to yield a complex, which are applied in the determination of many pharmaceutical compounds [26-34].

The present work aims to present two simple, rapid and sensitive method for the determination of MEM in pure form and in their pharmaceutical preparations and can be used for the quality control and assurance of these drugs in industry. The method $\mathrm{A}$ is based on the reaction of the drug with ninhydrin in $N, N^{\prime}-$ dimethylformamide (DMF) medium and heated on a water bath at $80 \pm 2{ }^{\circ} \mathrm{C}$ for 5 min, cooled to room temperature, and measuring the increase in absorbance at $595 \mathrm{~nm}$. In second method (B) MEM was reacted with ferric chloride solution, yellowish orange colored chromogen showed $\lambda_{\max }$ at $375 \mathrm{~nm}$, These methods are very simple in application and less expensive in comparison to the above mentioned techniques, at the same time offering a high degree of accuracy and precision when compared to the pharmacopoeia method and biological samples.<smiles>O=C1c2ccccc2C(=O)C1(O)O</smiles>

Scheme 2. The chemical structure of ninhydrin.

\subsection{Apparatus}

\section{Material And Methods}

All the spectral measurement were made using double-beam UV/Vis spectrophotometer (Biotech Engineering Ltd., UK), with wavelength range 190-1100 nm, spectral bandwidth $2.0 \mathrm{~nm}$, with scanning speed $400 \mathrm{~nm} / \mathrm{min}$, equipped with $10 \mathrm{~mm}$ matched quartz cells. A thermostat water bath, Buchi 461 water bath, Schwiz (France) was used to carry out the temperature studies and Magnetic Mix. 100, Thermo Scientific, UK.

\subsection{Reagents and materials}

All chemicals used were of analytical grade and all solutions were freshly prepared in doubly distilled water.

(1) Pure memantine $\mathrm{HCl}$ bulk powder, its purity was found to be $100.29 \pm 0.76(n=5)$ according to the HPLC procedures which obtained from Egyptian Organization for Control and Pharmaceutical Research - Egypt. Memantine $\mathrm{HCl}$ working solution prepared by dissolving $0.01 \mathrm{~g}$ of pure $\mathrm{MEM}$ in $50 \mathrm{~mL}$ of bidistilled water and complete to $100 \mathrm{~mL}$ with bidistilled water to obtain the working standard solution of concentration 100 $\mu \mathrm{g} / \mathrm{mL}$.

(2) The ninhydrin was obtained from E. Merck Darmstdt F. R. Germany. Stock solution of ninhydrin, $1.0 \mathrm{~g} \%$ (w/v), was prepared in $\mathrm{N}, \mathrm{N}^{\prime}$ - dimethylformamide (DMF) and further diluted according to the need with DMF.

(3) Ferric chloride was purchased from Merck-Schuchardt, Germany. Stock solution of ninhydrin, $1.0 \mathrm{~g} \%$ $(\mathrm{w} / \mathrm{v})$, was prepared in bidistilled water

\subsection{Method A}

\section{Analytical Procedures}

A volume of the drug $0.2-2.5 \mathrm{~mL}(100 \mu \mathrm{g} / \mathrm{mL}$ dissolved in bidistilled water $)$ was pipetted into a series of boiling test tubes. To each test tube $2.0 \mathrm{~mL}$ of $1 \%$ ninhydrin solution (which prepared in DMF) was added, mixed well and heated on a water bath at $80 \pm 2{ }^{\circ} \mathrm{C}$ for $5 \mathrm{~min}$. After heating the solution, tubes were cooled to room temperature. The content of the tube was transferred to a $10 \mathrm{~mL}$ volumetric flask and diluting to volume 
Spectrophotometric Determination of Alzheimer's Drug, Memantine Hydrochloride in Biological ..

with DMF. The absorbance of the complex product was measured at the recommended $\lambda_{\max } 595 \mathrm{~nm}$, against a reagent blank prepared in the same manner without addition of the drug.

\subsection{Method B}

Different aliquots $(0.3-9.7 \mu \mathrm{g} / \mathrm{mL})$ of MEM were transferred into a series of $25 \mathrm{~mL}$ volumetric flasks. To each flask, $3.0 \mathrm{~mL}$ of $1 \%$ ferric chloride solution was added, and remain $5 \mathrm{~min}$ at room temperature. The yellowish orange color was measured at $375 \mathrm{~nm}$ against reagent blank at room temperature.

\subsection{Procedure for tablets}

Twenty tablets were weighed and ground into a fine powder. A portion of the powder equivalent to 10 $\mathrm{mg}$ of MEM was accurately weighed into a $100 \mathrm{~mL}$ calibrated flask, $60 \mathrm{~mL}$ of water was added and the contents were shaken thoroughly for about $20 \mathrm{~min}$ to extract the drug. The contents were diluted to the mark, mixed well and filtered using a quantitative filter paper to remove insoluble residue. The filtrate containing $100 \mu \mathrm{g} / \mathrm{mL}$ of MEM was diluted stepwise to obtain $10 \mu \mathrm{g} / \mathrm{mL}$, and an appropriate aliquot was subjected to analysis by spectrophotometry using the procedures described above.

\subsection{Spiked plasma samples}

Aliquots of $1.0 \mathrm{~mL}$ of plasma were spiked with different concentration levels of MEM. The spiked plasma samples were treated with $0.1 \mathrm{~mL}$ of $70 \%$ perchloric acid and vortexed for $1.0 \mathrm{~min}$. The samples were centrifuged for $20 \mathrm{~min}$ at $13000 \mathrm{rpm}$. The supernatants were transferred into test tubes and neutralized with 1.0 $\mathrm{M} \mathrm{NaOH}$ solution.

\section{Results And Discussion}

Ninhydrin (2, 2-Dihydroxyindane-1, 3-Dione) is a chemical used to detect ammonia or primary and secondary amines. When reacting with these free amines, a deep blue or purple color known as Ruhemann's purple is produced. Ninhydrin is a well-established reagent for the determination of certain amines, amino acids and thiophenes [35] MEM does not absorb above $250 \mathrm{~nm}$, therefore derivatization with ninhydrin and ferric chloride was carried out to increase the spectrophotometric sensitivity with bathochromic shift to visible region. In MEM primary amine, reacts with ninhydrin (1\%) to produce a blue colored product, which absorbs maximally at $595 \mathrm{~nm}$. Under the specified experimental conditions. Similarly, MEM reacts with ferric chloride solution $(1 \%)$ at room temperature $\left(25^{\circ} \mathrm{C}\right)$ for $5 \mathrm{~min}$ and gives a yellowish complex with absorbance at $375 \mathrm{~nm}$. There is no report in literature on the interaction of MEM with iron.

\subsection{Method A}

The use of the ninhydrin for the detection and quantitative estimation of amino acids and imino acids depends on the formation of Ruhemann's purple [36]. The primary amino group of MEM reacted with 2 hydroxyindan-1,3-dione in alkaline medium to form the amino compound which condensed with ninhydrin to give diketohydrindylidene-diketohydrindamine (Scheme 3), which interacts with amino group of the drug resulting in the formation of a blue colored product (Ruhemann's purple) which absorbed maximally at $595 \mathrm{~nm}$.

Several parameters such as heating time and reagent concentration were optimized to achieve high sensitivity, stability, low blank reading and reproducible results.<smiles>O=C1c2ccccc2C(O)C1N=c1c(=O)c2ccccc2c1=O</smiles>

Scheme 3. diketohydrindylidene-diketohydrindamine.

\subsection{Effect of heating time}

The optimum reaction time was determined by heating the reaction mixture on water bath at $80 \pm 2{ }^{\circ} \mathrm{C}$, that complete color development was attained after $5 \mathrm{~min}$ of the heating and remained constant up to $30 \mathrm{~min}$. Therefore, the optimum heating time was fixed at about $5 \mathrm{~min}$ throughout the experiment. 


\subsection{Effect of the reagent concentration}

The effect of the ninhydrin concentration on the color development was investigated using different volumes (0.1-3.0 mL) of 1\% ninhydrin were added to a fixed amount of MEM $(10 \mu \mathrm{g} / \mathrm{mL})$. The results are presented in Fig. 1, showing that the highest and most stable absorbance was obtained after addition of $2.0 \mathrm{~mL}$ of $1 \%$ ninhydrin. A $2.0 \mathrm{~mL}$ of the reagent was used as an optimum value for color development.

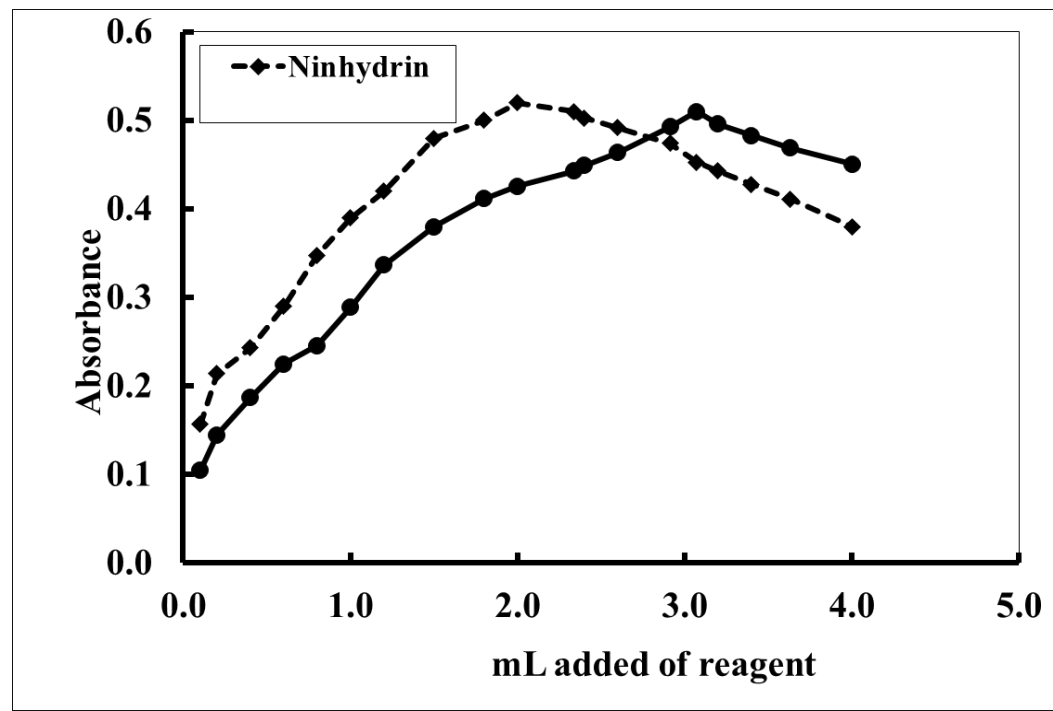

Figure 1: Effect of ninhydrin $(1 \%)$ volume $(\mathrm{MEM}=10 \mu \mathrm{g} / \mathrm{mL})$ and ferric chloride $(1 \%)$ volume $(\mathrm{MEM}=8.0$ $\mu \mathrm{g} / \mathrm{mL}$ ) on the absorbance of the colored product

\subsection{Method B}

The reaction between MEM and ferric chloride in water resulted in the formation of yellowish orange colored complex. To optimize the reaction conditions, different parameters such as temperature, reaction time, reagent concentration and color stability have been investigated. It was observed that the reaction occurred at room temperature $\left(25 \pm 2{ }^{\circ} \mathrm{C}\right)$. The optimum reaction time to develop maximum color was obtained in 5 minute at room temperature. The effect of the ferric chloride concentration on color development was investigated using 1.0-4.0 mL of 1\% ferric chloride. Absorbance remained constant after addition of $3 \mathrm{~mL}$ of $1 \%$ ferric chloride. Hence, the later concentration was adopted as the most suitable volume for maximum absorbance (Fig. 1).

Optical characteristics and statistical data for the regression equation of the proposed method are given in Table 1. Under optimum experimental condition, the values of slope of the regression equations of the proposed method indicate good sensitivity. The values of standard deviation and correlation coefficient obtained for regression equation exhibited good linearity of the method. To check the precision as well as accuracy of the proposed method, independent repeatability studies were performed with six repetitions (Table 2). High recovery and low standard deviation confirmed the suitability of the proposed method.

\subsection{Interference}

The effects of the common excipients that often accompany the studied drug (MEM) in various pharmaceutical dosage forms (commercial tablets) were tested for possible interference in the assay. An attractive feature of the procedure is its relative freedom from interference by the usual tablets diluents and excipients such as glucose, lactose, fructose and magnesium stearate. The common excipients present in injection formulations did not interfere in the determination of MEM.

\section{Analytical Data}

Beer's law was verified up to (0.4-19.3) $\mu \mathrm{g} / \mathrm{mL}$ and (0.3-9.7) $\mu \mathrm{g} / \mathrm{mL}$ of MEM with ninhydrin and ferric chloride, respectively (Fig. 2). The molar absorptivity $(\varepsilon)$ calculated and found to be $1.12 \times 10^{4} \mathrm{~L} / \mathrm{mol} . \mathrm{cm}$ and $1.73 \times 10^{4} \mathrm{~L} / \mathrm{mol} . \mathrm{cm}$ using ninhydrin and ferric chloride, respectively, indicating high sensitivity of the reagents under investigations for the determination of MEM. The regression equations $(\mathrm{A}=\mathrm{a}+\mathrm{bC})$ where $\mathrm{A}=$ absorbance, $\mathrm{a}=$ intercept, $\mathrm{b}=$ slope and $\mathrm{C}=$ concentration in $\mu \mathrm{g} / \mathrm{mL}$ ), calculated from the calibration graph, were evaluated and recorded in Table 1. 


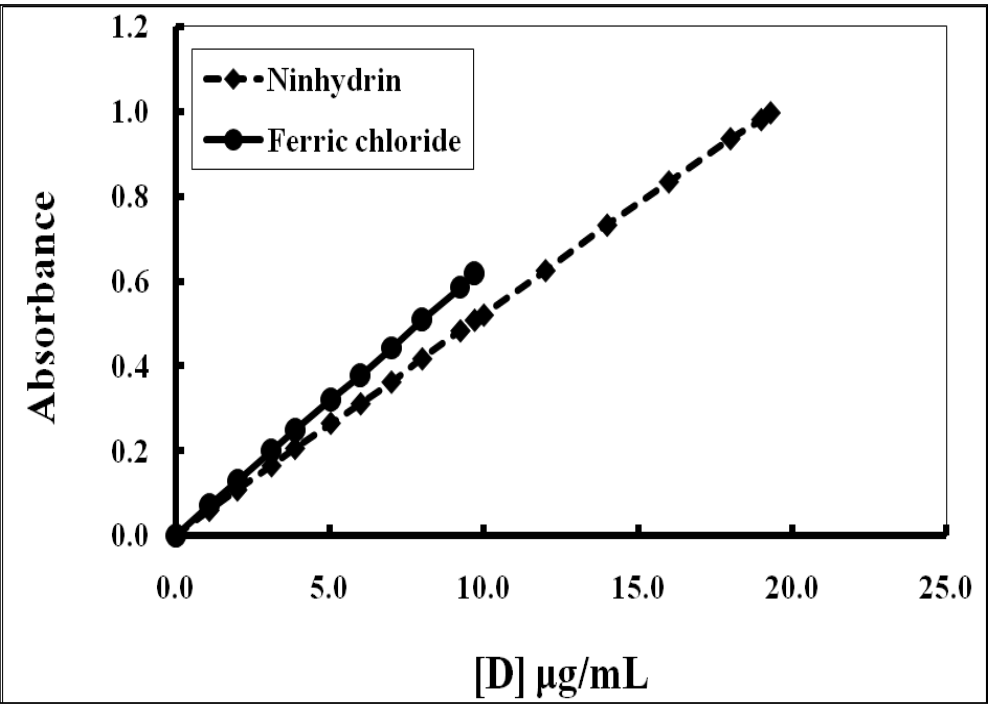

Figure 2: Validity of Beer's law for memantine $\mathrm{HCl}$ by two methods

The intercept of the lines were very small indicating that there is no systematic difference between determined and expected concentration within the investigated rang using the present method. For more accurate results, Ringbom concentration range was determined by plotting log [drug] in $\mu \mathrm{g} / \mathrm{mL}$ against $\%$ transmittance from which the linear portion of the curve gave accurate range for the determination of the drug under investigation Table 1. Statistical analysis of the results obtained, indicated that the proposed methods were accurate and precise. The limits of detection (LOD) and limits of quantitation (LOQ) were determined [37] using the formula:

$$
\mathrm{LOD} \text { or } \mathrm{LOQ}=\kappa \mathrm{SD}_{a} / b
$$

Where $\kappa=3$ for LOD and 10 for LOQ, $\mathrm{SD}_{a}$ is the standard deviation of the intercept, and $b$ is the slope. The limits of detection $(K=/ 3)$ and of quantitation $(K=/ 10)$ were established according to IUPAC definitions [38]. Based on the basis of six replicate measurements, the limit of detection was $0.011 \mu \mathrm{g} / \mathrm{mL}, 0.014 \mu \mathrm{g} / \mathrm{mL}$ and the limit of quantification was $0.037 \mu \mathrm{g} / \mathrm{mL}, 0.047 \mu \mathrm{g} / \mathrm{mL}$ for method A and B respectively. Both LOD and LOQ values confirmed the sensitivity of the proposed methods. In order to determine the accuracy and precision of the present method, solutions containing five different concentrations of drug were prepared and six replicate determinations, converting the usable concentration range, were carried out for the pure form and the pharmaceutical of the drugs under investigation. The recovery values almost reach $100 \%$ recovery, revealing a high accuracy of the results Table 2 .

Table 1. Analytical characteristics of the proposed methods.

\begin{tabular}{|c|c|c|}
\hline Parameter & Ninhydrin & Ferric chloride \\
\hline$\lambda_{\max }(\mathrm{nm})$ & 595 & 375 \\
\hline Stability $/ \mathrm{h}$ & 24 & 12 \\
\hline Beer's conc. range $\mu \mathrm{g} / \mathrm{mL}$ & $0.4-19.3$ & $0.3-9.7$ \\
\hline Ringbom optimum range $\mu \mathrm{g} / \mathrm{mL}$ & $0.7-17.9$ & $0.4-7.8$ \\
\hline Detection limits $\mathrm{ng} / \mathrm{mL}$ & 0.011 & 0.014 \\
\hline Quantification limits $\mu \mathrm{g} / \mathrm{mL}$ & 0.037 & 0.047 \\
\hline Molar absorptivity $\mathrm{L} / \mathrm{mol} . \mathrm{cm}$ & $1.12 \times 10^{4}$ & $1.73 \times 10^{4}$ \\
\hline Sandell sensitivity $\mathrm{ng} / \mathrm{cm}$ & 19.3 & 15.8 \\
\hline \multicolumn{3}{|l|}{ Regression equation ${ }^{a}$} \\
\hline Slope & 0.0517 & 0.0633 \\
\hline RSD \% of slope & 0.0093 & 0.0078 \\
\hline Intercept & 0.0037 & -0.0011 \\
\hline Correlation coefficient & 0.99995 & 0.99996 \\
\hline RSD \% & 0.88 & 1.03 \\
\hline Range of error \% & \pm 1.09 & \pm 1.17 \\
\hline Calculated t-values $(2.57)^{\mathrm{b}}$ & 1.11 & 0.96 \\
\hline Calculated F- test $(5.05)^{b}$ & 2.81 & 2.57 \\
\hline
\end{tabular}

${ }^{\mathrm{a}} \mathrm{A}=\mathrm{a}+\mathrm{bC}$, where $\mathrm{C}$ is the concentration in $\mu \mathrm{g} / \mathrm{mL}$

${ }^{\mathrm{b}}$ Values in parentheses are the theoretical values for $\mathrm{t}-$ and $\mathrm{F}$ - values at $95 \%$ confidence limits and five degrees of freedom 
Spectrophotometric Determination of Alzheimer's Drug, Memantine Hydrochloride in Biological ..

Table 2. Evaluation of the accuracy and precision of the proposed procedure.

\begin{tabular}{|c|c|c|c|c|c|}
\hline Method & Taken $\mu \mathrm{g} / \mathrm{mL}$ & Recovery \% & RSD $^{\mathrm{a}}$ & RE\% $^{\mathrm{b}}$ & Confidence limits $^{c}$ \\
\hline & 5.00 & 100.4 & 0.36 & 0.30 & $05.02 \pm 0.0150$ \\
$\mathrm{~A}$ & 10.0 & 99.5 & 0.24 & 0.25 & $09.95 \pm 0.0245$ \\
& 15.0 & 99.93 & 0.10 & 0.23 & $14.99 \pm 0.0340$ \\
\hline & 3.0 & 98.67 & 0.61 & 0.65 & $2.96 \pm 0.01918$ \\
$B$ & 6.0 & 100.5 & 0.57 & 0.47 & $6.03 \pm 0.02831$ \\
& 9.0 & 100.33 & 0.40 & 0.43 & $9.03 \pm 0.03848$ \\
\hline
\end{tabular}

${ }^{a}$ Relative standard deviation for six determinations

${ }^{\mathrm{b}}$ Relative error

${ }^{c} 95 \%$ confidence limits and five degrees of freedom

\subsection{Applications}

The proposed method was successfully applied to determine MEM in its dosage forms in spiked serum plasma. The accuracy of the proposed methods was evaluated by applying standard addition technique, in which variable amounts of the drug were added to the previously analyzed portion of pharmaceutical preparations and in spiked serum plasma samples. The validity of the present method was tested by standard addition method. For this purpose, solutions containing three different concentrations of MEM were prepared by adding a known amount of pure drug to the pre-analyzed commercial dosage forms and determined in six replicates. The results are summarized in Table 3.

\subsection{Analysis of dosage forms}

The obtained satisfactory validation results made the proposed methods suitable for the routine quality control analysis of MEM and its dosage forms pharmaceutical formulations (Alzmenda and Memexa 10 $\mathrm{mg} /$ tablet). The results obtained by the proposed methods were statistically compared with those obtained by the official pharmacopoeia method [39]. In the t- and F-tests, no significant differences were found between the calculated and theoretical values of both the proposed and the reported methods at 95\% confidence level [40] level as recorded in Table 4. This indicated similar precision and accuracy in the analysis of MEM in its formulations. It is evident from the results that all the proposed methods are applicable to the analysis of MEM in its tablets with comparable analytical performance. However, the critical recommendations of these methods might be based on the experimental conditions and the ultimate sensitivity that determines the amount of specimen required for analysis. This indicates the high accuracy and precision of the present method.

Table 3. Determination of MEM in pharmaceutical formulations using standard addition technique (Taken 6.0

\begin{tabular}{|c|c|c|c|c|c|}
\hline \multirow[b]{2}{*}{ Samples } & \multirow{2}{*}{$\begin{array}{l}\text { Added } \\
\mu \mathrm{g} / \mathrm{mL}\end{array}$} & \multicolumn{2}{|c|}{$\mathrm{A}$} & \multicolumn{2}{|c|}{$\mathrm{B}$} \\
\hline & & $\begin{array}{l}\text { Found* } \\
\mu \mathrm{g} / \mathrm{mL}\end{array}$ & $\begin{array}{c}\text { Recovery } \\
\%\end{array}$ & $\begin{array}{l}\text { Found* } \\
\mu \mathrm{g} / \mathrm{mL}\end{array}$ & $\begin{array}{c}\text { Recovery } \\
\%\end{array}$ \\
\hline \multirow{4}{*}{$\begin{array}{l}\text { Alzmenda } \\
10 \mathrm{mg} / \text { tablet }^{1}\end{array}$} & 0.0 & 6.01 & 100.2 & 5.97 & 99.50 \\
\hline & 1.0 & 7.02 & 100.3 & 6.98 & 99.71 \\
\hline & 2.0 & 7.94 & 99.25 & 7.97 & 99.63 \\
\hline & 3.0 & 9.02 & 100.2 & 8.97 & 99.67 \\
\hline \multirow{4}{*}{$\begin{array}{l}\text { Memexa } \\
10 \mathrm{mg} / \text { tablet }^{2}\end{array}$} & 0.0 & 5.97 & 99.50 & 5.99 & 99.83 \\
\hline & 1.0 & 6.98 & 99.71 & 7.02 & 100.3 \\
\hline & 2.0 & 7.97 & 99.63 & 7.95 & 99.48 \\
\hline & 3.0 & 9.03 & 100.3 & 8.94 & 99.33 \\
\hline \multirow{4}{*}{ Spiked plasma pimple } & 0.0 & 5.97 & 99.50 & 5.98 & 99.67 \\
\hline & 1.0 & 7.01 & 100.1 & 7.02 & 100.3 \\
\hline & 2.0 & 8.02 & 100.3 & 7.94 & 99.25 \\
\hline & 3.0 & 8.97 & 99.67 & 9.02 & 100.2 \\
\hline
\end{tabular}

* Average of six determinations

${ }^{1}$ Marcyrl Pharmaceutical Industries, El-Obour City, Egypt

${ }^{2}$ Copad Egypt for Trade and Pharmaceutical Industries (Copad Pharma), Egypt

\subsection{Analysis of spiked plasma samples}

The high sensitivity attained by the proposed methods allows the determination of MEM, in biological fluids. The method was used to determine the amount of MEM in a healthy male $12 \mathrm{~h}$ after an intake of one tablet of MEM, which contains $10 \mathrm{mg}$ MEM, was detected and the results were summarized in Table 3.

The calculated standard deviations are compared with those obtained by the pharmacopoeia method of MEM [39]. 
Spectrophotometric Determination of Alzheimer's Drug, Memantine Hydrochloride in Biological ..

Table 4. Determination of MEM in tablet $(10 \mathrm{mg} / \mathrm{tablet})$ and spiked plasma by the proposed and official method

\begin{tabular}{|c|c|c|c|}
\hline \multirow[t]{2}{*}{ Parameter } & \multicolumn{3}{|c|}{ Alzmenda $10 \mathrm{mg} /$ tablet $^{1}$} \\
\hline & Method A & Method B & Official method \\
\hline Recovery $\%^{\text {a }}$ & $99.6 \pm 1.32$ & $100.2 \pm 1.31$ & $99.4 \pm 1.82$ \\
\hline \pm Standard Deviation & 0.69 & 0.77 & 1.30 \\
\hline Number of experiments & 6 & 6 & 6 \\
\hline Variance & 0.86 & 0.96 & 1.70 \\
\hline t-test ${ }^{b}$ & 1.14 & 0.96 & 1.61 \\
\hline \multirow[t]{2}{*}{ F-value $^{b}$} & 2.45 & 2.53 & 2.60 \\
\hline & \multicolumn{3}{|c|}{ Memexa $10 \mathrm{mg} /$ tablet $^{2}$} \\
\hline Recovery $\%^{\mathrm{a}}$ & $100.1 \pm 0.85$ & $99.6 \pm 1.26$ & $100.2 \pm 1.98$ \\
\hline \pm Standard Deviation & 0.83 & 0.96 & 1.11 \\
\hline Number of experiments & 6 & 6 & 6 \\
\hline Variance & 1.28 & 0.97 & 1.75 \\
\hline t-test ${ }^{b}$ & 0.69 & 0.94 & 1.10 \\
\hline \multirow[t]{2}{*}{ F-value $^{b}$} & 1.29 & 2.36 & 2.49 \\
\hline & \multicolumn{3}{|c|}{ Spiked plasma pimples } \\
\hline Mean recovery $\%^{\text {a }}$ & $99.9 \pm 0.75$ & $99.8 \pm 1.07$ & $100.2 \pm 1.26$ \\
\hline \pm Standard Deviation & 1.09 & 0.95 & 1.44 \\
\hline Number of experiments & 6 & 6 & 6 \\
\hline Variance & 1.22 & 0.80 & 1.55 \\
\hline t-test $^{b}$ & 1.32 & 1.29 & 1.64 \\
\hline F-value $^{b}$ & 2.49 & 2.30 & 2.69 \\
\hline
\end{tabular}

${ }^{a}$ Average values of six determinations were used for the official and the proposed methods, respectively

${ }^{\mathrm{b}}$ Theoretical values for $\mathrm{t}$ and $\mathrm{F}$ at $95 \%$ confidence limit are 2.57 and 5.05, respectively

${ }^{1}$ Marcyrl Pharmaceutical Industries, El-Obour City, Egypt

${ }^{2}$ Copad Egypt for Trade and Pharmaceutical Industries (Copad Pharma), Egypt

\section{Conclusions}

The proposed methods for the estimation of MEM using ninhydrin and ferric chloride are advantageous over many of the reported methods, due to its sensitivity, rapidity and good agreement with the pharmacopoeia methods. The high recovery percentage and lows relative standard deviation reflect the high accuracy and precision of the proposed method. Moreover, the method is easy, applicable to wide ranges of concentration, beside less time consuming and depend on simple reagents, which are available. This offering economic and acceptable method for the routine determination of the cited drug, Beer's law up to $0.3 \mu \mathrm{g} / \mathrm{mL}$. So it is recommended for the routine determination in pure samples and in their pharmaceutical formulations.

\section{References}

[1]. R. Barry, D. Rachelle, S. Albrecht, S. Frederick, F. Steven, J.M. Hans, Memantine in moderate-to-severe Alzheimer's disease. The New Eng. J. of Med. 2003, 348, 1333-1341.

[2]. S. Sonkusare, C. Kaul, P. Ramarao, Dementia of Alzheimer's disease and other neurodegenerative disorders - memantine, a new hope, Pharma. Res., 2005, 51, 1-17.

[3]. H.F. Steven, Evaluation of memantine for the treatment of Alzheimer's disease, Exp. Opin. on Pharm., 4, 2305-2313, (2003).

[4]. S.S. Lon, S. Philip, W. Michael, Treatment with cholinesterase inhibitors and memantine of patients in the Alzheimer's disease neuroimaging initiative, Arch. of Neuro. 2011, 68, 58-66.

[5]. S.P. Sulochana, K. Sharma, R. Mullangi, et al., Review of the validated HPLC and LCMS/MS methods for determination of drugs used in clinical practice for Alzheimer's disease, Biomed. Chromatogr. 2014, 28, 1431-1490.

[6]. N. Bhavil, A. Singh, P. Santhakumar, et al., A validated stability-indicating reverse phase HPLC assay method for the determination of memantine hydrochloride drug substance with UV-detection using precolumn derivatization technique, Anal. Chem. Ins., 2010, 5, 37-45.

[7]. M. Xie, W. Zhou, X. Tong, et al., High-performance liquid chromatographic determination of memantine hydrochloride in rat plasma using sensitive fluorometric derivatization. J. of Sep. Sci., 2011, 34, 241-246.

[8]. Y.G Veetharam, and S. Praveen, A pre-column derivatization technique for the development and validation of a stability indicating HPLC-UV method for the determination of memantine in bulk and formulations by using (2-napthoxy) acetyl chloride, Der Pharma Chemica, 2014, 6(4), 169-180.

[9]. R.F. Suckow, M.F. Zhang, E.D. Collins, M.W. Fischman, T.B. Cooper, Sensitive and selective liquid chromatographic assay of memantine in plasma with fluorescence detection after pre-column derivatization, J. of Chrom. B. 1999, 729, 217-224.

[10]. A. Zarghi, A. Shafaati, S. Foroutan, et al., Sensitive and rapid HPLC method for determination of memantine in human plasma using OPA derivatization and fluorescence detection: application to pharmacokinetic studies. Scientia Pharmaceutica, 2010, 78, 847-856.

[11]. B. Puente, E. Hernandez, S. Perez, et al., Determination of memantine in plasma and vitreous humour by HPLC with precolumn derivatization and fluorescence detection, J. of Chrom. Sci., 2011, 49, 745-752.

[12]. A. Almeida, D. Campos, G. Bernasconi, et al., Determination of memantine in human plasma by liquid chromatographyelectrospray tandem mass spectrometry: application to a bioequivalence study, J. of Chrom. B, Ana. Tech. in the Biomed. and Life sci., 2007, 848, 311-316.

[13]. R. Pan, T. Chian, B. Kuo et al., Determination of memantine in human plasma by LC-MS-MS: application to a pharmacokinetic study, Chromatographia, 2009, 70, 783-788. 
Spectrophotometric Determination of Alzheimer's Drug, Memantine Hydrochloride in Biological ..

[14]. M.J. Koeberle, P.M. Hughes, C.G. Wilson, G.G. Skellern, Development of a liquid chromatography-mass spectrometric method for measuring the binding of memantine to different melanins, J. of Chrom. B. 787 (2003) 313-322.

[15]. K. Kumar, B. Challa, C. Rao, et al., Bioanalytical method development and validation of memantine in human plasma by high performance liquid chromatography with tandem mass spectrometry: Application to bioequivalence study, J. of Anal. Meth. in Chem., 2012(2012), 101-149.

[16]. H. Leis, G. Fauler, W. Windischhofer, Quantitative analysis of memantine in human plasma by gas chromatography/negative ion chemical ionization/mass spectrometry, J. of Mass Spec., 2002, 37, 477-480.

[17]. H. Yeh, Y. Yang, S. Chen, Simultaneous determination of memantine and amantadine in human plasma as fluorescein derivatives by micellar electrokinetic chromatography with laser-induced fluorescence detection and its clinical application, Electrophoresis, 2010,31, 1903-1911.

[18]. H.A. Omara and A.S. Amin, Extractive-Spectrophotometric Methods for Determination of Alzheimer's Drug in Pharmaceutical Formulations and in Biological Samples Using Sulphonphthalein Acid Dyes, Canad. Chem. Trans., 2016, 4, 17-31.

[19]. H.A. Omara, Spectrophotometric microdetermination of Alzheimer's drug memantine $\mathrm{HCl}$ in biological samples, Analy. Chem. Lett. http://dx.doi.org/10.1080/22297928.2017.1279566.

[20]. R. El-Nashar, A. El-Tantawy, S. Hassan, Potentiometric membrane sensors for the selective determination of memantine hydrochloride in pharmaceutical preparations, Int. J. Electrochem. Sci., 2012, 7, 10802-10817.

[21]. M.R. Ganjali, F. Aboufazeli, S. Riahi, et al., Memantine potentiometric membrane sensor for memantine pharmaceutical analysis, computational investigation, Intern. J. of Elect. Sci., 2009, 4, 1138-1152.

[22]. V. Jagathi, B. Anupama, P. Praveen, et al., Spectrophotometric determination of memantine in bulk and in pharmaceutical formulations, Inter. J. of Current Pharm. Res., 2010, 2(4), 17-18.

[23]. K. Michail, H. Daabees, Y. Beltagy, et al., Spectrophotometric and spectrofluorimetric determination of memantine hydrochloride in bulk and pharmaceutical preparations, Inter. J. of Phar. and Pharm. Sci., 2011,3,180-185.

[24]. E. Kaiser, R. Colescott, C. Bossinger, et al., Color test for detection of free terminal amino groups in the solid-phase synthesis of peptides, Anal. Biochem., 1970, 34, 595-601.

[25]. H.A. Omara, and A.S. Amin, New, simple and validated spectrophotometric method for determination of amikacin in biological samples and its pharmaceutical formulations, Inter. J. of Pharm. \& Biol. Sci. Res. \& Devl. Ref., 2013, 1(4), 2347-4785.

[26]. M. S. Arayne, N. Sultana, F. Siddiqui, et al., Spectrophotometric techniques to determine tranexamic acid: Kinetic studies using ninhydrin and direct measuring using ferric chloride, J. of Mole. Struc., 2008, 891(1-3), 475-480.

[27]. N. Rahman, and M. Kashif, Application of ninhydrin to spectrophotometric determination of famotidine in drug formulations, $I l$ Farmaco, 2003, 58(10), 1045-1050.

[28]. N. Rahman, and S. Azmi, Spectrophotometric method for the determination of amlodipine besylate with ninhydrin in drug formulations, Il Farmaco, 2001, 56(10), 731-735.

[29]. S. Won, J. Min, S. Hee, et al., Colorimetric determination of amino acids using genipin from Gardenia jasminoides, Anal. Chimica Acta, 2003, 480(2), 267-274.

[30]. L. Martínez, P. Falcó, and A. Cabeza, Comparison of several methods used for the determination of cephalosporins. Analysis of cephalexin in pharmaceutical samples, J. Pharm. Biomed. Anal., 2002, 29(3), 405-423.

[31]. H. Abdel-Wadood, N. Mohamed, and A. Mahmoud, Validated spectrofluorometric methods for determination of amlodipine besylate in tablets, Spectrochimica Acta Part A: Mole. and Biom. Spect., 2008, 70(3), 564-570.

[32]. K. Prashanth, K. Basavaiah, and M. Raghu, Utilization of $N$-bromosuccinimide as a brominating agent for the determination of sumatriptan succinate in bulk drug and tablets, Inter. J. of Anal. Chem., (2013), Article ID 934357, 11 pages http://dx.doi.org/10.1155/2013/934357.

[33]. S. Patel, N. Patel, Spectrophotometric determination of cephalexin using ninhydrine reagent in tablet dosage form. Inter, Res. J. of Phar., 2011, 2(9), 123-126.

[34]. M. Arayn, N. Sultana, F. Siddiqui, et al., Spectrophotometric method for the determination of drug with ninhydrin in drug formulations, Analytical techniques in pharmaceutical analysis, Arab. J. of Chem., In Press, 2013.

[35]. F. Fiegel, Spot Tests in Organic Analysis, Elsevier Publishing Co., London, 1960.

[36]. D. McCaldin. The Chemistry of Ninhydrin, Chem. Rev., 1960, 60, 39-51.

[37]. H. Irving, H. Freiser, T. West, (Eds.). "IUPAC Compendium of Analytical Nomenclature", Definitive Rules. Pergamon Press, Oxford, 1981.

[38]. IUPAC. Nomenclature, symbols, units and their usage in spectrochemical analysis-II. Data interpretation analytical chemistry division, Spectrochimica Acta, B, 1978, 33, 241-245.

[39]. The British Pharmacopoeia (BP), Her Majesty's Stationary 432 Office, I. The British Pharmacopoeia, London, 2007.

[40]. J.C. Miller, J.N. Miller, "Statistics and Chemometrics for Analytical Chemistry", $5^{\text {th }}$ edn., Prentice Hall, England, 2005. 